\title{
A DIVERSIDADE CULTURAL ENTRE OS PAÍSES DE LÍNGUA ESPANHOLA NO CONTEXTO SOCIOEDUCATIVO
}

\section{ARTIGO ORIGINAL}

CORREA, Silvana Serra Costa ${ }^{1}$

CORREA, Silvana Serra Costa. A diversidade cultural entre os países de língua espanhola no contexto socioeducativo. Revista Científica Multidisciplinar Núcleo do Conhecimento. Ano 05, Ed. 05, Vol. 12, pp. 138-145. Maio de 2020. ISSN: 24480959, Link de acesso: https://www.nucleodoconhecimento.com.br/letras/contextosocioeducativo

\section{RESUMO}

O presente trabalho apresenta a importância em difundir o ensino da Língua Espanhola nas escolas públicas em Manaus- Amazonas, apresentando a importância de conhecer o ensino da língua Espanhola, inserindo os procedimentos de construção de métodos para aplicar nas escolas com o objetivo de valorizar o aprendizado. $\mathrm{O}$ artigo "A diversidade Cultural entre os Países de Língua Espanhola no Contexto Socioeducativo" aborda o interesse dos alunos para o desenvolvimento dos estudos nos fundamentos teóricos e na aplicabilidade do projeto embasando um diálogo à luz dos conhecimentos científicos e autores referenciado no presente artigo. Por tanto procurou-se a problematizar através de pesquisas em livros, internet e apresentações como: músicas, teatro e feiras culturais onde demonstram os resultados alcançados e o conhecimento adquirido através do domínio do idioma.

Palavras-chave: Ensino, cultura, conhecimento, espanhol, diversidade.

1 Pós-Graduada em Psicopedagogia Educacional. Graduada em letras- língua espanhola. 


\section{INTRODUÇÃO}

A língua espanhola vem se expandindo pelo mundo todo ao longo dos anos, se pode observar que há necessidade de uma boa parte da sociedade ter conhecimento de outros idiomas. Desta forma, a importância do ensino da língua espanhola no âmbito educacional traz um significado fundamental para a vida social do corpo discente e contribui para o desenvolvimento integral destes sujeitos.

Para se realizar o presente trabalho, objetivou-se a Incentivar a busca de informações através de pesquisas bibliográficas e Internet, valorizando o conhecimento a respeito da música, da literatura e da diversidade da cultura espanhola.

Por tanto, esse tema foi escolhido com a intenção de buscar as informações através de fundamentos teóricos, como também enfatizando o aprendizado do idioma através da música, da leitura e do conhecimento do contexto histórico da cultura espanhola. $O$ projeto expressa 0 interesse dos alunos para aprender e compreender 0 conhecimento da língua espanhola, buscando as informações por aprendizados escritos, opiniões, ideias e valores embasados em teorias científicas e também por experiências vivenciadas por outras pessoas.

A escola é um meio de vida social que reflete no comportamento e desempenho da sociedade, ou seja, favorecendo a comunicação, redimensionando as relações entre comunidade e escola, desta maneira, a relevância de identificar os aspectos positivos e negativos de uma escola participativa perante o desenvolvimento da sociedade, se faz importante para alcançar objetivos que venham refletir sobre as conquistas e inovações da educação escolar.

A pesquisa será de abordagem qualitativa, a mesma será realizada através da consulta de artigos, livros e internet conforme a temática estudada. Confecção de vestuário para apresentação teatral dos Contos Infantis; Confecção de cenários para apresentação teatral dos Contos Infantis; Confecção de painéis para a Feira Hispânica; Confecção de camisas para apresentação da Feira Hispânica; 
Microsistem, CDs, Data show, computador, caixa de som e microfones para apresentação de música e danças.

\section{A IMPORTÂNCIA DA LÍNGUA ESPANHOLA NA ATUALIDADE}

A língua espanhola é oficialmente utilizada em 21 países: Espanha, México, Guatemala, Costa Rica, Panamá, Nicarágua, El Salvador, Honduras, Cuba, República Dominicana, Colômbia, Venezuela, Equador, Peru, Bolívia, Chile, Paraguai, Argentina, Uruguai, Guiné Equatorial e Porto Rico. Não deixando de ressaltar que é a segunda língua mais falada nos Estados Unidos.

Conforme a lei 11.161 que foi decreta pelo Congresso Nacional e sancionada em agosto de 2005 pelo presidente Lula:

Art. $1^{\circ} \mathrm{O}$ ensino da língua espanhola, de oferta obrigatória pela escola e de matrícula facultativa para o aluno, será implantado, gradativamente, nos currículos plenos do ensino médio. $\S 1^{\circ} \mathrm{O}$ processo de implantação deverá estar concluído no prazo de cinco anos, a partir da implantação desta Lei. § 2 É facultada a inclusão da língua espanhola nos currículos plenos do ensino fundamental de $5 \mathrm{a}$ a 8 a séries.

Em Manaus, as escolas da rede pública estadual de ensino aderiram o ensino da língua espanhola nos primórdios do ano letivo de 2005. Com a necessidade de prepararmos nossos alunos para o mercado de trabalho e acompanhar o desenvolvimento social dos mesmos, e ainda de se buscar a expansão da própria escola, seus conhecimentos acerca da música, da literatura, das festas, danças típicas e costumes de cada país que tem o espanhol como idioma oficial.

Durante as aulas sempre há muito interesse por parte dos alunos em saber sobre as diferenças em termos de crenças, costumes e tradições entre o Brasil e os países de idioma espanhol como, por exemplo, o "Día de los muertos" no México, que é verdadeiramente festejado com enfeites, comidas e muita alegria, diferente do Dia de Finados, no Brasil, que é visto como sinônimo de tristeza e saudades. Levando em 
consideração diferenças como estas, é que sentimos a necessidade de desenvolver um projeto de pesquisa, onde possamos incentivá-los a buscar estas informações e apresentá-las através da música, do teatro e de uma Feira Hispânica.

Segundo Junger (2005), os pontos de contato (léxico e estruturas morfossintáticas) entre o espanhol e português favorecem também uma aproximação mais imediata ao idioma estrangeiro por parte de nossos alunos, permitindo desde muito cedo o acesso a textos retirados de documentos de uso cotidiano de hispano-falantes, com certo grau de complexidade.

Desta forma, o Projeto que será denominado: "A Diversidade Cultural Entre Os Países De Língua Espanhola No Contexto Socioeducativo", tem como principal objetivo valorizar o ensino da língua espanhola no contexto cultural de forma prática, ampla e dinâmica, uma vez que a execução do mesmo servirá também como requisito para nota parcial. Este trabalho constará a princípio de pesquisas bibliográficas e na Internet sobre músicas, danças, literatura e diferentes costumes entre os países hispânica. Em seguida, se trabalhará na confecção de vestuário para apresentação teatral dos contos infantis e na exposição da Feira Hispânica. Promover um aprendizado através de coleta de informações dos próprios alunos é enriquecê-los do mais nobre dos valores da vida: o conhecimento. Este trabalho será direcionado a alunos do Ensino Médio, distribuídos da seguinte forma: 1o ano (Canciones Españolas); $2^{\circ}$ ano (Literatura: Teatro- Cuentos Infantiles) e $3^{\circ}$ ano (Feria Hispánica).

Neste sentido, para Morin (2007), a compreensão é, a um só tempo, meio e fim da comunicação humana. O planeta necessita, em todos os sentidos, de compreensão mútua. Considerando a importância da educação para a compreensão, em todos os níveis educativos e em todas as idades, o desenvolvimento da compreensão pede a reforma das mentalidades. Seguindo essa compreensão, aborda-se a relevância deste projeto para que todos do âmbito educacional possam apropriar-se do conhecimento das diversidades culturais do aprendizado da língua espanhola. 


\subsection{RELEVÂNCIA PARA OS ALUNOS}

Ao final do primeiro ano do ensino médio, os alunos já possuem conhecimento suficiente para interpretar textos curtos (canções) e para produção oral de nível inicial. Sendo assim estarão preparados para demonstrar o domínio vocabular através de músicas e coreografias.

No decorrer do segundo ano do ensino médio, os alunos terão acesso aos verbos nos pretéritos (Imperfecto, Perfecto Compuesto e Indefinido), que estão relacionados aos conteúdos programáticos do $2^{\circ}$ ano. Desta forma, demonstrarão o aprendizado de tais conteúdos através da prática oral, ou seja, da apresentação teatral em língua espanhola, fazendo referência à literatura- "Cuentos Infantiles".

No terceiro e último ano do ensino médio, os alunos já estão aptos para demonstrar todo o conhecimento oral e escrito adquiridos, e por isso a importância de incentiválos à pesquisa a respeito da diversidade cultural através de uma Feira Hispânica.

\subsubsection{RELEVÂNCIA PARA A ESCOLA}

A execução do projeto acerca da diversidade cultural, abrangerá todos os alunos do ensino médio do turno integral, contribuindo diretamente no aprendizado dos alunos executores, e indiretamente aos que assistirão as apresentações, assim como gestores, secretária, professores e demais profissionais da escola.

\section{ETAPAS DO PROJETO}

1- Apresentar as propostas do projeto aos alunos, informando-os sobre os objetivos da execução do mesmo;

2- Dividir os grupos e sortear os temas a serem pesquisados;

3- Realizar o Projeto: "A Diversidade Cultural Entre Os Países De Língua Espanhola No Contexto Sócio educativo" envolvendo música, teatro e feira cultural com as três séries do ensino médio, respectivamente. 
4- Elaborar relatórios informando os resultados do projeto e o desempenho dos grupos envolvidos, que servirá de requisito para nota parcial do terceiro bimestre.

\subsection{CRONOGRAMA DAS ATIVIDADES}

\section{METAS}

1

2

3

4

5

6

\section{ATIVIDADES}

Apresentação do projeto aos alunos- início do $1^{\circ}$ bimestre; Divisão dos grupos e sorteio dos temas a serem pesquisados- Fim do $1^{\circ}$ Bimestre;

Pesquisa Bibliográfica- durante todo $\circ 2^{\circ}$ bimestre; CANCIONES

ESPAÑOLAS ( $1^{\text {a }}$ SÉRIE), CUENTOS INFANTILES ( $2^{\text {a }}$ SÉRIE) e FERIA HISPÁNICA ( $3^{\text {a }}$ SÉRIE).

Realização do projeto: MUSICAL - CANCIONES ESPAÑOLAS ( $1^{\text {a }}$ série) Final do $2^{\circ}$ bimestre.

Realização do projeto: TEATRO - CUENTOS INFANTILES ( $2^{\mathrm{a}}$ série) - Final do $2^{\circ}$ bimestre.

Realização do projeto: FERIA CULTURAL "LA DIVERSIDAD CULTURAL ENTRE LOS PAÍSES DE LENGUA ESPAÑOLA EN EL CONTEXTO SOCIOEDUCATIVO - $\left(3^{\text {a }}\right.$ serie $)$ - Final de $3^{\circ}$ bimestre.

O Art. 205, da Constituição Federal, diz que: "A educação, direito de todos e dever do Estado e da família, será promovida e incentivada com a colaboração da sociedade visando ao pleno desenvolvimento da pessoa, seu preparo para o exercício da cidadania e sua qualificação para o trabalho." (BRASIL, 1998). Deste modo, todos devem exercer o seu papel para efetivar o desempenho escolar e social da criança.

Os direitos da criança e a participação da família e da escola, como visto, têm diretrizes próprias que regem e garantem o progresso educacional infanto-juvenil, referências bibliográficas e estudos orientadas ao assunto. Porém, a prática fica sob a responsabilidade dos pais, gestores e educadores. 


\section{CONSIDERAÇÕES FINAIS}

Ao término dos estudos e pesquisas direcionadas para as apresentações dos trabalhos, os discentes brasileiros e, sobretudo amazonenses, sentem-se aptos a exercer a oralidade do idioma espanhol sem medo. Sentem- se preparados para enfrentar os desafios das provas externas como: SIS, PSC, MACRO DA UFAM (Universidade Federal do Amazonas) e UEA (Universidade Estadual do Amazonas) em língua espanhola. O Ensino do Espanhol tem sido um diferencial em nossa região e propor desafios aos nossos alunos os tem oportunizado a uma aprendizagem satisfatória e impulsionado nossos jovens à obtenção de excelentes resultados inclusive em termos profissionais.

\section{REFERÊNCIAS}

BRASIL. Lei № 11.161, de 5 de agosto de $2005<$ http://www.planalto.gov.br/ccivil_03/_Ato2004-2006/2005/Lei/L11161.htm > acesso em 28/05/2019.

BRASIL. LEI de Diretrizes e Bases da Educação Nacional: Lei no 9394/96. Disponível em <HTTP:// www.google.com.br> acesso em 10 de dezembro de 2013.

BRASIL. Constituição Federal De 1988. https://www.senado.leg.br/atividade/const/con1988/con1988_05.10.1988/ind.asp. Acesso: 29 de julho de 2019.

JUNGER, C. S. V. Reflexões sobre o ensino de E/LE no Brasil: propostas governamentais, formação docente e práticas em sala de aula. In: Anuario brasileño de estudios hispânicos. XV. Brasília, 2005.

MORIN, Edgar. Os sete saberes necessários à educação do futuro. 12 ed. São Paulo: Cortez; Brasília, DF: UNESCO, 2007. 
Proposta Curricular de Língua Espanhola para o Ensino Médio, - Manaus: SeducSecretaria de Estado e Qualidade do Ensino, 2012.

RAPAPORT, Ruth. Comunicação e tecnologia no ensino de línguas. Curitiba: Ibpex, 2008.

Enviado: Junho, 2019.

Aprovado: Maio, 2020. 